\title{
Expression profile of cytochrome P450s and effects of polycyclic aromatic hydrocarbons and antiepileptic drugs on CYP1 expression in MOG-G-CCM cells
}

\author{
Shusuke Ozawa ${ }^{\mathrm{a}, \mathrm{b}}$, Satoshi Yamaori ${ }^{\mathrm{a}, \mathrm{b}, *}$, Kaori Aikawa ${ }^{\mathrm{b}}$, Shinobu Kamijo ${ }^{\mathrm{b}}$, Shigeru Ohmori ${ }^{\mathrm{a}, \mathrm{b}}$ \\ ${ }^{a}$ Department of Pharmacy, Shinshu University Hospital, 3-1-1 Asahi, Matsumoto 390-8621, Japan \\ ${ }^{\mathrm{b}}$ Department of Biochemical Pharmacology and Toxicology, Graduate School of Medicine, Shinshu University, 3-1-1 Asahi, Matsumoto, 390-8621 Matsumoto, Japan
}

\section{A R T I C L E I N F O}

\section{Keywords:}

CYP1B1

CYP1A1

Astrocytes

Polycyclic aromatic hydrocarbons

Antiepileptic drugs

Aryl hydrocarbon receptor

Induction

Histone deacetylase inhibition

\begin{abstract}
A B S T R A C T
Aims: This study was performed to investigate the expression profile of cytochrome P450 (CYP) isoforms and effects of polycyclic aromatic hydrocarbons (PAHs) and antiepileptic drugs on CYP1 expression in human astrocytoma MOG-G-CCM cells.

Main methods: CYP1A1 and CYP1B1 expression were determined by quantitative real-time polymerase chain reaction, Western blotting, and immunocytochemistry.

Key findings: MOG-G-CCM cells expressed various CYP isoforms. Among the CYP isoforms analyzed, CYP1B1 showed the highest expression level, followed by CYP1A1. Furthermore, CYP1B1 was localized in both the endoplasmic reticulum and mitochondria. 3-Methylcholanthrene (3-MC), benz $[a]$ anthracene (B $[a] \mathrm{A})$, benzo[a] pyrene $(\mathrm{B}[a] \mathrm{P})$, and valproic acid (VPA) increased the expression of CYP1B1 and CYP1A1. The potent aryl hydrocarbon receptor antagonist GNF351 significantly suppressed the 3-MC- and VPA-mediated upregulation of CYP1B1 and CYP1A1. In addition, VPA potentiated the induction of CYP1B1 and CYP1A1 by 3-MC, B[a]A, and B $[a] \mathrm{P}$, although the augmentation of CYP1A1 was more remarkable than that of CYP1B1. In contrast, other antiepileptic drugs (carbamazepine, lamotrigine, levetiracetam, phenytoin) did not affect the 3-MC-mediated upregulation of CYP1B1 and CYP1A1. VPA is known to act as a histone deacetylase (HDAC) inhibitor. Therefore, the effects of trichostatin A, a representative HDAC inhibitor, on CYP1 induction by 3-MC were examined. Trichostatin A enhanced the 3-MC-mediated upregulation of CYP1A1 but not CYP1B1.

Significance: These results partially indicated that VPA may augment the PAH-mediated induction of CYP1B1 and CYP1A1 through the activation of transcription by HDAC inhibition.
\end{abstract}

\section{Introduction}

Epilepsy is a chronic neurological disorder that affects more than 70 million people around the world [1]. This disorder is characterized by seizures resulting from abnormal neuronal activity in the brain and requires treatment with antiepileptic drugs (AEDs). It has been reported that the prevalence of smoking is higher in epileptic patients than in the general population in certain regions of some countries [2-4]. Smoking predisposes people to many diseases, including cardiovascular disease, cerebrovascular disease, chronic obstructive pulmonary disease, and cancers [5]. Recently, tobacco smoking has also been suggested to be a risk factor for epilepsy and epileptic seizures [6-8]. Therefore, it is clinically important to identify the effects of tobacco smoking and administration of AEDs on brain function.

Drug-metabolizing enzymes are mainly expressed in the liver and small intestine. These enzymes convert foreign chemicals into more hydrophilic compounds to rapidly excrete them from the body. Cytochrome P450 (CYP) enzymes play a major role in this biotransformation. CYP enzymes are a superfamily of heme proteins that are responsible for the oxidative metabolism of a wide variety of endogenous and exogenous compounds, including steroids, fatty acids, vitamins, drugs, procarcinogens, and xenobiotic chemicals [9]. CYP enzymes are expressed in various tissues in addition to the liver and small intestine. For example, CYP enzymes are known to be involved in the metabolism of various compounds in the brain, including centrally acting drugs, neurotoxins, neurotransmitters, and neurosteroids [10]. In general, the expression of CYP enzymes is induced by specific chemicals. In particular, the CYP1 family, which is comprised of CYP1A1, CYP1A2, and CYP1B1, is known to be induced by polycyclic aromatic hydrocarbons (PAHs) contained in tobacco smoke [11-13]. A recent

\footnotetext{
* Corresponding author at: Department of Pharmacy, Shinshu University Hospital, 3-1-1 Asahi, Matsumoto 390-8621, Japan.

E-mail address: syamaori@shinshu-u.ac.jp (S. Yamaori).
} 
Table 1

Primers used for qPCR.

\begin{tabular}{|c|c|c|c|c|}
\hline Genes & Forward primers & Reverse primers & Length (bp) & References \\
\hline GAPDH & GAGTCAACGGATTTGGTCGT & GACAAGCTTCCCGTTCTCAG & 185 & [17] \\
\hline CYP1A1 & GTCATCTGTGCCATTTGCTTTG & CAACCACCTCCCCGAAATTATT & 97 & [18] \\
\hline CYP1A2 & TGTTCAAGCACAGCAAGAAGG & TGCTCCAAAGACGTCATTGAC & 92 & [18] \\
\hline CYP1B1 & СТССТССТСTTCACCAGGTATCCT & CATACAAGGCAGACGGTCCCT & 90 & [19] \\
\hline CYP2A6 & GAGTTCCTGTCACTGTTGCG & GTCCTGGCAGGTGTTTCATC & 109 & [20] \\
\hline CYP2B6 & CCCCAAGGACACAGAAGTATTTC & GATTGAAGGCGTCTGGTTTTTC & 83 & [18] \\
\hline CYP2C8 & CTCGGGACTTTATGGATTGC & CAGTGCCAACCAAGTTTTCA & 93 & [20] \\
\hline СYP2C9 & TGCTTCCTGATGAAAATGGA & TCTCTGTCCCAGCTCCAAAC & 106 & [20] \\
\hline CYP2C19 & TTGCTTCCTGATCAAAATGG & GTCTCTGTCCCAGCTCCAAG & 108 & {$[20]$} \\
\hline CYP2D6 & TGCATGTGGACTTCCAGAAC & CAGCCCATTGAGCACGAC & 113 & [20] \\
\hline CYP2E1 & GACCACCAGCACAACTCTGA & CССАATCACССТGTCAATTT & 97 & [20] \\
\hline CYP2J2 & GGCAACTTCTTCCTTGTGGA & TGTCACCAAGCTCCAAGCTA & 97 & [20] \\
\hline CYP3A4 & ССТTACACATACACACССTTTGGAAG & TGGTTGAAGAAGTCCTCCTAAGCT & 171 & [21] \\
\hline CYP3A5 & ССTTACATATACACACCCTTTGGAAC & GTTGAAGAAGTCCTTGCGTGTC & 169 & {$[21]$} \\
\hline CYP3A7 & GGGAAATGCTTTGTCCTTCC & AGCCAGCATAGGCTGTTGAC & 109 & [20] \\
\hline CYP4A11 & CTCAAAGCCCTCCAGCAGT & ACCCATTTCTGAATCCGTTG & 104 & [20] \\
\hline CYP4A22 & ATAGGCAGTGGCTGCTCAAA & GAATCCGTTGTAGCTCCTGG & 108 & {$[20]$} \\
\hline CYP4F2 & GGCAGGAGGTGCAAGAACT & TCATGCACATGGTCAGGAAG & 93 & {$[20]$} \\
\hline CYP4F3 & CAAGAGCTTCTGAAGGACCG & ССTCAGGCTCTCCTTAATGC & 96 & [20] \\
\hline CYP4F8 & TGAAGGACCGTGAGCCTAAA & GAATGTAGGGATTGGGGGAT & 110 & {$[20]$} \\
\hline CYP4F11 & CAAGAGCTTCTGAAGGACCG & GCAGGCTCTCCTTAATGCAC & 94 & [20] \\
\hline CYP4F12 & CAAGAGCTTCTGAAGGACCG & GGGATGTAACCTCAGGCTCTC & 105 & {$[20]$} \\
\hline CYP46A1 & TCTGTCCCAGGCAGTGAAAC & AGCTGCTTCСTCTTCCCTG & 90 & [20] \\
\hline
\end{tabular}

study showed that the expression levels of CYP1A1 and CYP1B1 in the prefrontal cortex and/or amygdala tended to be higher in smokers than in non-smokers [14]. These findings suggest that PAHs contained in tobacco smoke may be involved in the regulation of cerebral CYP1 gene expression. As CYP1 enzymes are capable of hydroxylating the neurosteroid 17ß-estradiol $[15,16]$, brain CYP1 enzymes have been suggested to play a role in maintaining the function of neurosteroids. If hyperupregulation of CYP1 gene expression by interaction between tobacco smoke components and drugs occurs in the human brain, biological responses to neurosteroids may be altered and hence affect brain function. However, the effects of PAHs on cerebral CYP1 gene expression have not been extensively investigated. In particular, there have been no reports regarding the role of the interaction of PAHs with AEDs in the regulation of cerebral CYP1 gene expression.

In this study, we investigated the expression profile of CYP isoforms and effects of PAHs and AEDs on CYP1 expression in the human astrocytoma cell line MOG-G-CCM.

\section{Materials and methods}

\subsection{Reagents and antibodies}

3-Methylcholanthrene (3-MC) was purchased from Nacalai Tesque (Kyoto, Japan). Aryl hydrocarbon receptor (AhR) antagonist III (GNF351) was obtained from Merck KGaA (Darmstadt, Germany). Other reagents and antibodies were obtained from the following sources: acenaphthene, acenaphthylene, benz $[a]$ anthracene $(\mathrm{B}[a] \mathrm{A})$, benzo $[a]$ pyrene $(\mathrm{B}[a] \mathrm{P})$, fluoranthene, fluorene, 1-methylnaphthalene, naphthalene, phenanthrene, pyrene, carbamazepine (CBZ), and $16 \%$ (w/v) methanol-free paraformaldehyde solution from Wako Pure Chemical Industries, Ltd. (Osaka, Japan); anthracene, 2-methylnaphthalene, lamotrigine (LTG), 5,5-diphenylhydantoin sodium salt (phenytoin; PHT), valproic acid sodium salt (VPA), and an anti-actin $(20-33)$ antibody produced in rabbit from Sigma-Aldrich (St. Louis, MO, USA); levetiracetam (LEV) from LKT Laboratories (St. Paul, MN, USA); trichostatin A (TSA) from Cayman Chemical (Ann Arbor, MI, USA); goat anti-rabbit IgG-HRP (catalog\# sc-2004) and rabbit polyclonal antibodies against human CYP1B1 (H-105) from Santa Cruz Biotechnology, Inc. (Santa Cruz, CA, USA); normal goat serum blocking solution from Vector Laboratories (Burlingame, CA, USA); mouse monoclonal antibodies against human cytochrome $c$ oxidase subunit IV
(COX IV) (mAbcam33985) and human calnexin (AF18) from Abcam (Cambridge, MA, USA); Alexa Fluor ${ }^{\circledR}$ 488-conjugated goat anti-mouse IgG $(\mathrm{H}+\mathrm{L}) \mathrm{F}\left(\mathrm{ab}^{\prime}\right)_{2}$ fragment from Cell Signaling Technology (Beverly, MA, USA); Alexa Fluor ${ }^{\circledast}$ 546-conjugated goat anti-rabbit IgG $(\mathrm{H}+\mathrm{L})$ highly cross-absorbed antibody from Molecular Probes (Eugene, OR, USA); Hoechst 33258 from Setareh Biotech (Eugene, OR, USA); baculovirus-infected insect cell microsomes expressing human CYP1B1 with human NADPH-CYP reductase (CYP1B1 Supersomes ${ }^{\mathrm{TM}}$ ) from Corning Incorporated (Woburn, MA, USA). All other chemicals and reagents were of the highest quality commercially available.

\subsection{Cell culture and drug treatments}

The human astrocytoma cell line MOG-G-CCM was obtained from the European Collection of Authenticated Cell Cultures (Salisbury, UK). MOG-G-CCM cells were maintained in Dulbecco's modified Eagle's medium/nutrient mixture F-12 Ham (Sigma-Aldrich) supplemented with 10\% heat-inactivated fetal bovine serum (BioWest, Nuaillé, France) and penicillin/streptomycin (Gibco, Grand Island, NY, USA) in a humidified atmosphere containing $5 \% \mathrm{CO}_{2}$ at $37{ }^{\circ} \mathrm{C}$. The culture medium was replaced with fresh medium every 2-3 days. Cells were seeded into 6-well plates $\left(1 \times 10^{5}\right.$ cells/well $)$ and cultured for $24 \mathrm{~h}$. Cells were treated with PAHs, AEDs, and/or TSA in serum-free medium for up to $48 \mathrm{~h}$. Antagonism experiments were carried out as described below. Cells were treated with GNF351 in the presence or absence of 3MC and VPA for $12 \mathrm{~h}$. With the exception of VPA that was dissolved in serum-free medium, all test chemicals were prepared in dimethylsulfoxide. Controls were prepared with equivalent volumes $(0-0.525 \%)$ of dimethylsulfoxide only, which did not significantly influence cell viability and expression levels of target genes at the final volume used.

\subsection{RNA analysis}

Total RNA was extracted from MOG-G-CCM cells using TRIzol reagent (Invitrogen, Carlsbad, CA, USA) according to the manufacturer's protocol. Reverse transcription reactions were conducted with a High Capacity RNA-to-cDNA Kit (Applied Biosystems, Foster City, CA, USA). Quantitative real-time polymerase chain reaction (qPCR) was performed using an ABI 7300 real-time PCR system (Applied Biosystems) with a KAPA SYBR ${ }^{\circledR}$ Fast qPCR Kit (Kapa Biosystems, Boston, MA, USA) according to the manufacturer's instructions. The primers used are 
summarized in Table 1. Relative expression levels of target genes were quantified by the comparative $\mathrm{Ct}$ method $\left(2^{-\Delta \Delta \mathrm{Ct}}\right)$, and samples were normalized relative to glyceraldehyde-3-phosphate dehydrogenase (GAPDH).

\subsection{Western blotting analysis}

Whole-cell lysates were prepared from MOG-G-CCM cells by scraping in $100 \mu \mathrm{l}$ of lysis buffer $(150 \mathrm{mM}$ sodium chloride, $50 \mathrm{mM}$ Tris$\mathrm{HCl}, \mathrm{pH} 8.0,0.1 \%$ sodium dodecyl sulfate, $5 \mathrm{mM}$ ethylenediamine tetraacetic acid, $1 \%$ sodium deoxycholate, $1 \%$ Triton X-100, $2 \mathrm{mM}$ phenylmethylsulfonyl fluoride, protease inhibitor cocktail (cOmplete ${ }^{\mathrm{TM}}$ Mini, Roche Diagnostics, Meylan, France), and 2.5 g/l sodium azide). Sodium dodecyl sulfate-polyacrylamide gel electrophoresis was performed using $10 \%$ polyacrylamide gels as described previously [22]. Total cellular protein $\left(15 \mu \mathrm{g}\right.$ protein) and CYP1B1 Supersomes ${ }^{\mathrm{TM}}(10$ fmol P450) were separated and transferred onto polyvinylidene fluoride membranes. Membranes were blocked at room temperature for $1 \mathrm{~h}$ with $5 \%$ nonfat milk in phosphate buffered saline (PBS) containing $0.1 \%$ Tween $20(\mathrm{PBS} / \mathrm{T})$ and then incubated overnight at $4{ }^{\circ} \mathrm{C}$ with primary antibodies against CYP1B1 (1:1000 dilution) or actin (1:2000 dilution) in PBS/T. Membranes were incubated at room temperature for $1 \mathrm{~h}$ with goat anti-rabbit IgG-HRP (1:2000 dilution for CYP1B1, 1:5000 dilution for actin) as a secondary antibody in PBS/T. Conjugated horseradish peroxidase was detected using Immobilon ${ }^{\mathrm{TM}}$ Western Chemiluminescent HRP Substrate (Millipore, Billerica, MA, USA), and bands were scanned with a ChemiDoc XRS Plus system (Bio-Rad Laboratories, Inc., Hercules, CA, USA).

\subsection{Immunocytochemistry}

MOG-G-CCM cells were seeded into 24 -well plates $\left(2 \times 10^{4}\right.$ cells/ well) and cultured for $24 \mathrm{~h}$. Cells were fixed with $4 \%$ paraformaldehyde in PBS at room temperature for $20 \mathrm{~min}$ and then incubated in blocking buffer $(0.3 \%$ Triton X-100 and 5\% normal goat serum in PBS) at room temperature for $1 \mathrm{~h}$. Fixed cells were incubated overnight at $4{ }^{\circ} \mathrm{C}$ with primary antibodies against CYP1B1, COX IV, or calnexin (1:200 dilution) in blocking buffer. Fixed cells were incubated at room temperature for $1 \mathrm{~h}$ with Alexa Fluor ${ }^{\circledR}$ 488-conjugated goat anti-mouse IgG or Alexa Fluor ${ }^{\circledR}$ 546-conjugated goat anti-rabbit IgG (1:1000 dilution) as secondary antibodies in blocking buffer. After counterstaining of nuclei with Hoechst $33258(5 \mu \mathrm{g} / \mathrm{ml})$, fluorescence images were obtained using a Biozero BZ-8100 (Keyence, Osaka, Japan) at $20 \times$ magnification.

\subsection{Statistical analysis}

Data are expressed as the mean \pm standard deviation (S.D.) of triplicate determinations. The results were analyzed by one-way analysis of variance followed by Dunnett's or Bonferroni's multiple comparison test with statistical significance set at $p<0.05$. All statistical analyses were performed with GraphPad Prism 5.02 software (GraphPad Software Inc., San Diego, CA, USA).

\section{Results}

\subsection{Expression profile of human CYP isoforms in MOG-G-CCM cells}

The relative expression levels of human CYP isoforms in MOG-GCCM cells were measured by qPCR. CYP1A1, CYP1A2, CYP1B1, CYP2B6, CYP2C8, CYP2E1, CYP2J2, CYP3A4, CYP3A5, CYP4F2, CYP4F3, CYP4F11, CYP4F12, and CYP46A1 expression were detected in MOG-G-CCM cells (Table 2). Among the CYP isoforms analyzed, CYP1B1 showed the highest expression level followed by CYP1A1.
Table 2

Relative expression of individual CYP mRNAs in MOG-GCCM cells.

\begin{tabular}{ll}
\hline Isoforms & Relative mRNA levels \\
\hline CYP1A1 & $23.44 \pm 4.55$ \\
CYP1A2 & $0.11 \pm 0.12$ \\
CYP1B1 & $5677.31 \pm 529.38$ \\
CYP2A6 & N.D. \\
CYP2B6 & $3.50 \pm 0.91$ \\
CYP2C8 & $7.43 \pm 2.37$ \\
CYP2C9 & N.D. \\
CYP2C19 & N.D. \\
CYP2D6 & N.D. \\
CYP2E1 & $1.19 \pm 0.67$ \\
CYP2J2 & $4.55 \pm 0.69$ \\
CYP3A4 & $1.03 \pm 0.29$ \\
CYP3A5 & $4.76 \pm 0.99$ \\
CYP3A7 & N.D. \\
CYP4A11 & N.D. \\
CYP4A22 & N.D. \\
CYP4F2 & $2.57 \pm 2.20$ \\
CYP4F3 & $1.08 \pm 0.51$ \\
CYP4F8 & N.D. \\
CYP4F11 & $0.68 \pm 0.68$ \\
CYP4F12 & $0.53 \pm 0.34$ \\
CYP46A1 & $1.63 \pm 0.58$ \\
\hline
\end{tabular}

Values are expressed as fold change (mean \pm S.D. of triplicate determinations) in gene expression relative to CYP3A4.

N.D.; not detectable (relative mRNA levels $<0.01$ ).

\subsection{Intracellular localization of human CYP1B1 in MOG-G-CCM cells}

In general, hepatic CYP enzymes involved in drug metabolism are predominantly localized in the endoplasmic reticulum (ER; also termed microsomes), although a small portion of these enzymes are also found in mitochondria [23]. On the other hand, drug-metabolizing brain CYP enzymes have been reported to be localized in both the ER and mitochondria [24,25]. Therefore, to determine the subcellular distribution of CYP1B1 most highly expressed in MOG-G-CCM cells, we carried out immunocytochemical analysis. CYP1B1 was widely distributed in the cells; some was co-localized with the ER marker calnexin [26] (Fig. 1A), and some was co-localized with the mitochondrial marker COX IV [27] (Fig. 1B).

\subsection{Inducibility of human CYP1 expression by 3-MC and tobacco smoke containing PAHs in MOG-G-CCM cells}

The inducibility of CYP1B1 and CYP1A1 by 3-MC, a representative PAH inducing CYP1 expression [28], was evaluated in MOG-G-CCM cells. 3-MC increased the expression of CYP1B1 mRNA in a concentration-dependent manner, reaching the maximum level at $0.3 \mu \mathrm{M}$ (Fig. 2A). The expression reached a maximum level at $24 \mathrm{~h}$ after 3-MC treatment (Fig. 2B). Treatment with 3-MC also upregulated the expression of CYP1B1 protein in a concentration-dependent manner (Fig. 2C). Under the same conditions as CYP1B1 mRNA, 3-MC showed concentration-dependent induction of CYP1A1 mRNA (Supplementary material $1 \mathrm{~A}$ ). The expression level reached a maximum at $12 \mathrm{~h}$ after treatment with 3-MC (Supplementary material 1B).

The activation of CYP1 gene transcription by 3-MC is mediated by the AhR, which is a transcription factor of the basic-helix-loop-helix/ Per-Arnt-Sim family [29]. To determine whether the AhR was involved in the induction of CYP1B1 and CYP1A1 by 3-MC in MOG-G-CCM cells, the effects of an AhR antagonist on 3-MC-mediated upregulation were examined. We used GNF351 as an AhR antagonist. This compound is a high-affinity AhR ligand without agonist activity and has the capacity to repress both xenobiotic response element-dependent and -independent AhR functions [30]. GNF351 significantly suppressed the 
(A)

Nuclei
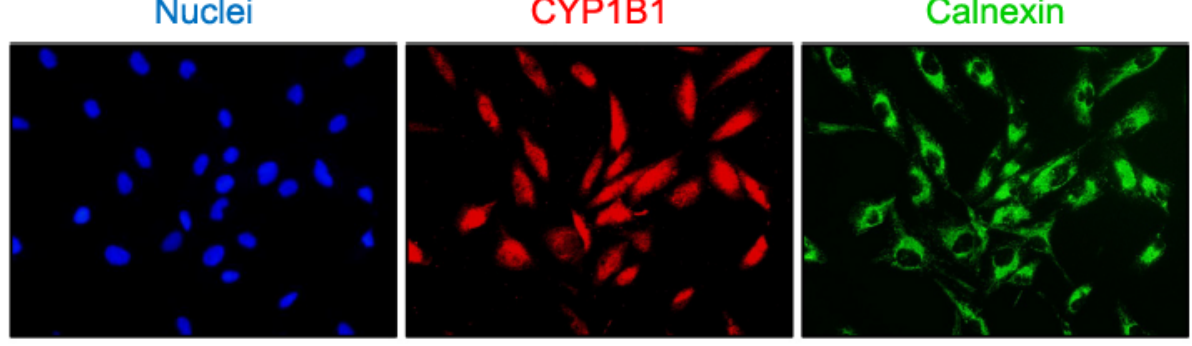

Calnexin

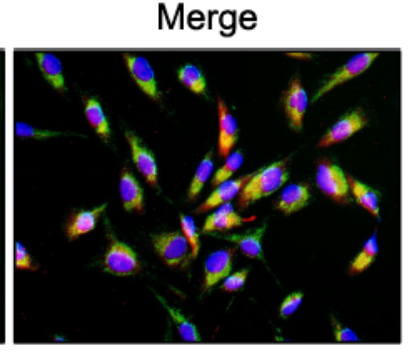

(B)
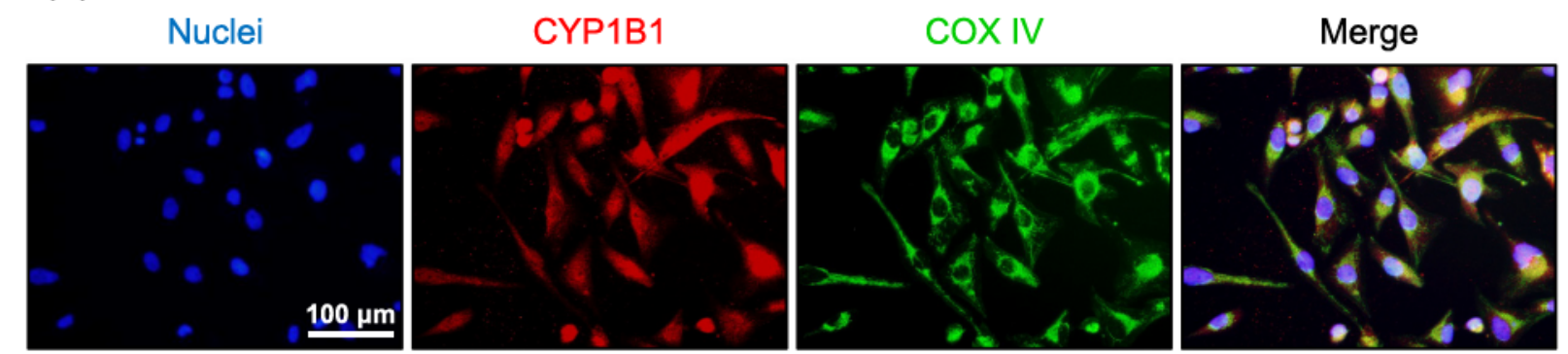

Fig. 1. Immunocytochemical detection of CYP1B1, calnexin, and COX IV in MOG-G-CCM cells. MOG-G-CCM cells were incubated with antibodies against CYP1B1 (red) and calnexin (ER marker, green) (A) or antibodies against CYP1B1 (red) and COX IV (mitochondrial marker, green) (B) for double-labeled immunofluorescence. The cell nuclei were stained with Hoechst 33258 (blue). The merged images show CYP1B1 (yellow) localized in the ER (A) and mitochondria (B). (For interpretation of the references to colour in this figure legend, the reader is referred to the web version of this article.)

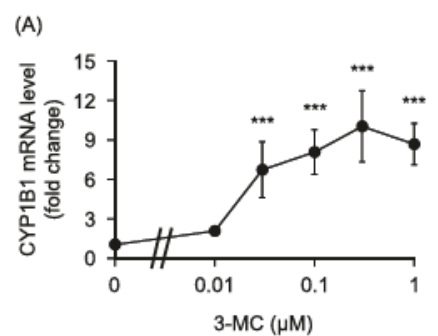

(C)

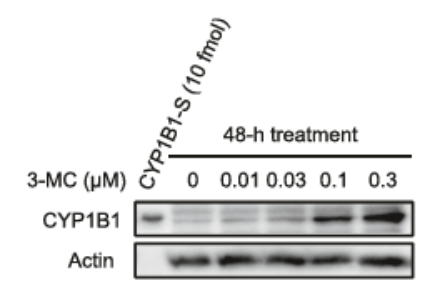

(B)

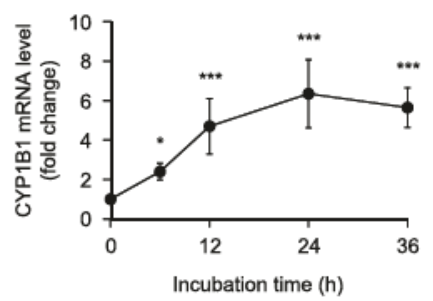

(D)

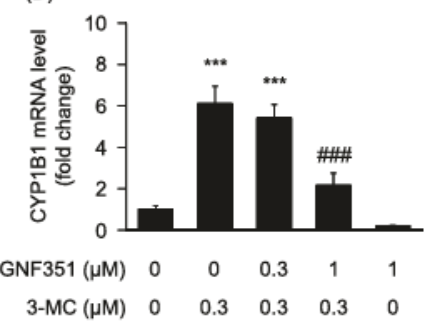

Fig. 2. Effects of 3-MC on expression of CYP1B1 in MOG-G-CCM cells. (A) MOG-G-CCM cells were treated with 3-MC for $24 \mathrm{~h}$. Expression level of CYP1B1 mRNA was determined by $\mathrm{qPCR}$. Data are expressed as the mean \pm S.D. of triplicate determinations. ${ }^{* * *} p<0.001$ vs. control (Dunnett's test). (B) MOGG-CCM cells were treated with 3 -MC $(0.3 \mu \mathrm{M})$ for the indicated periods. Expression level of CYP1B1 mRNA was determined by qPCR. Data are expressed as the mean \pm S.D. of triplicate determinations. ${ }^{*} p<0.05,{ }^{* * *} p<0.001$ vs. control (Dunnett's test). (C) MOG-G-CCM cells were treated with 3-MC for $48 \mathrm{~h}$. CYP1B1 and actin proteins were detected by Western blotting. CYP1B1-S; CYP1B1 Supersomes ${ }^{\mathrm{Tm}}$. (D) MOG-G-CCM cells were treated with GNF351 in the presence or absence of 3-MC for $12 \mathrm{~h}$. Expression level of CYP1B1 mRNA was determined by $\mathrm{qPCR}$. Data are expressed as the mean \pm S.D. of triplicate determinations. ${ }^{* * *} p<0.001$ vs. control, ${ }^{\# \#} p<0.001$ vs. 3-MC alone (Bonferroni's test).

induction of CYP1B1 mRNA by 3-MC (Fig. 2D). Treatment with GNF351 also significantly reduced the expression level of CYP1A1 mRNA induced by 3-MC (Supplementary material 1C).
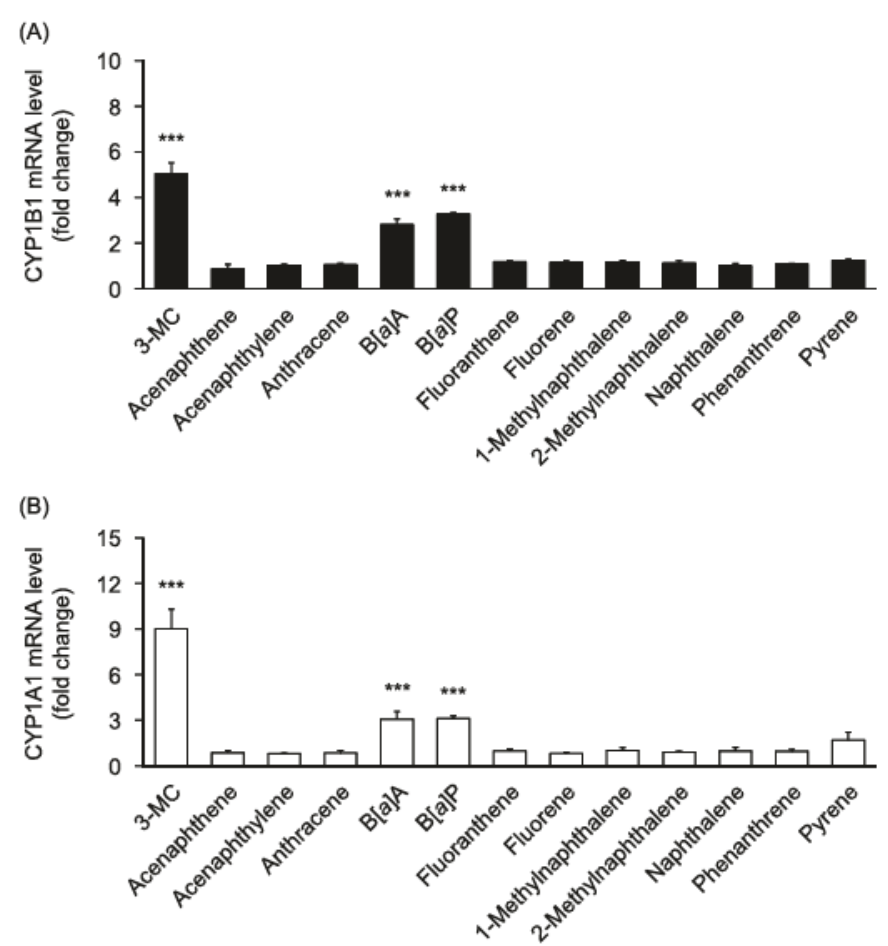

Fig. 3. Effects of tobacco smoke containing PAHs on CYP1 expression in MOGG-CCM cells. MOG-G-CCM cells were treated with 3-MC or major PAHs contained in tobacco smoke $(0.3 \mu \mathrm{M})$ for $24 \mathrm{~h}$. Expression levels of CYP1B1 (A) and CYP1A1 (B) mRNAs were determined by qPCR. Data are expressed as the mean \pm S.D. of triplicate determinations ( $n=4$ per an experiment). ${ }^{* * *} p<0.001$ vs. control (Dunnett's test).

The inducibilities of CYP1B1 and CYP1A1 by major twelve PAHs contained in tobacco smoke [31] were investigated in MOG-G-CCM cells. Among the PAHs tested, $\mathrm{B}[a] \mathrm{A}$ and $\mathrm{B}[a] \mathrm{P}$ significantly upregulated the expression of CYP1B1 and CYP1A1 mRNAs (Fig. 3). 

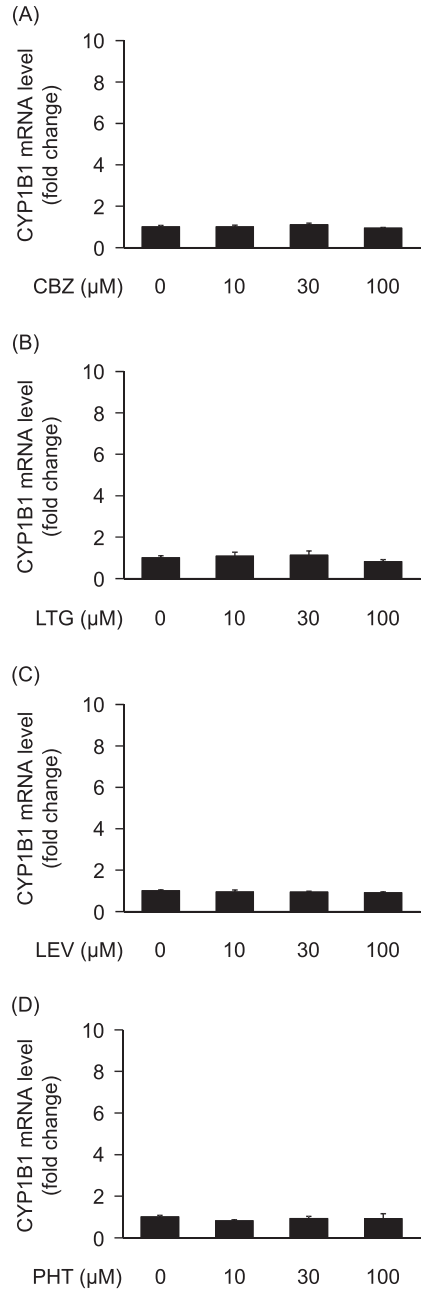

(E)

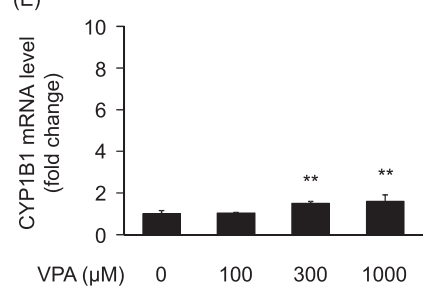

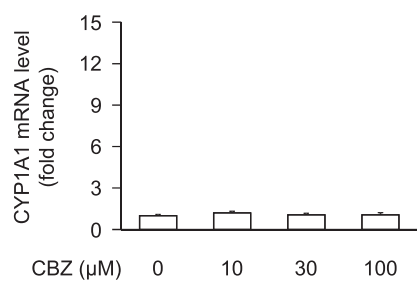
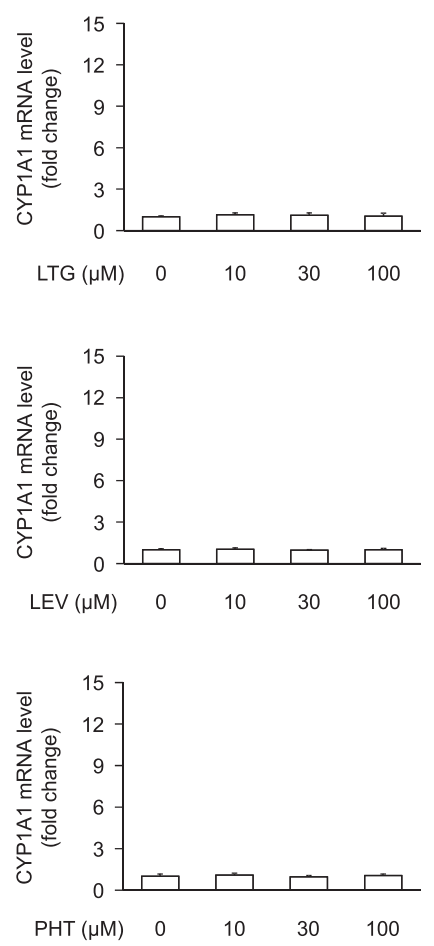

Fig. 4. Effects of AEDs on CYP1 expression in MOG-G-CCM cells. MOG-G-CCM cells were treated with CBZ (A), LTG (B), LEV (C), PHT (D), and VPA (E) for 12 h. Expression levels of CYP1B1 and CYP1A1 mRNAs were determined by qPCR. Data are expressed as the mean \pm S.D. of triplicate determinations (n $=3-4$ per an experiment). ${ }^{* *} p<0.01,{ }^{* * *} p<0.001$ vs. control (Dunnett's test).

\subsection{Effects of AEDs on human CYP1 expression in MOG-G-CCM cells}

The inducibilities of CYP1B1 and CYP1A1 by AEDs were evaluated in MOG-G-CCM cells. We set the concentrations of CBZ, LTG, LEV, PHT, and VPA based on these clinically relevant concentrations [32]. CBZ, LTG, LEV, and PHT did not influence the expression of CYP1B1 and CYP1A1 mRNAs under the current conditions (Fig. 4A-D, Supplementary material 2A-D). On the other hand, treatment with VPA for $12 \mathrm{~h}$ significantly induced the expression of CYP1B1 and CYP1A1 (Fig. 4E), whereas treatment for $24 \mathrm{~h}$ showed an increase in CYP1A1 mRNA but not CYP1B1 mRNA level (Supplementary material 2E). To determine the involvement of AhR in VPA-mediated induction of CYP1B1 and CYP1A1, the effects of an AhR antagonist on their upregulation were investigated. Treatment with GNF351 significantly repressed the

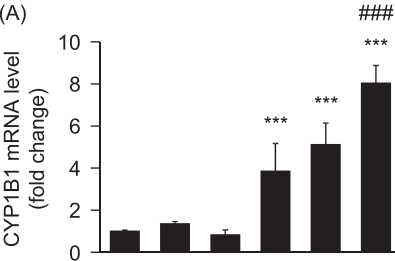

$\operatorname{VPA}(\mu \mathrm{M}) \quad 0 \quad 3001000 \quad 0 \quad 3001000$ $\begin{array}{lllllll}3-\mathrm{MC}(\mu \mathrm{M}) & 0 & 0 & 0 & 0.3 & 0.3 & 0.3\end{array}$

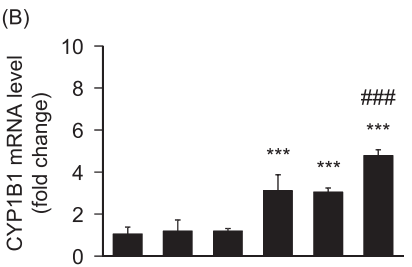

$\operatorname{VPA}(\mu \mathrm{M}) \quad 0 \quad 3001000 \quad 0 \quad 3001000$

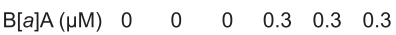

(C)

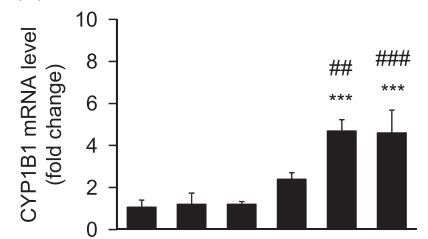

$\operatorname{VPA}(\mu \mathrm{M}) \quad 0 \quad 300 \quad 1000 \quad 0 \quad 3001000$ $\mathrm{B}[\mathrm{a}] \mathrm{P}(\mu \mathrm{M}) \quad 0 \quad 0 \quad 000.3 \quad 0.3 \quad 0.3$

Fig. 5. Effects of VPA on CYP1 induction by PAHs in MOG-G-CCM cells. MOGG-CCM cells were treated with VPA in the presence or absence of 3-MC (A), B [a]A (B), and B[a]P (C) for $24 \mathrm{~h}$. Expression levels of CYP1B1 and CYP1A1 mRNAs were determined by qPCR. Data are expressed as the mean \pm S.D. of triplicate determinations ( $\mathrm{n}=3-4$ per an experiment). ${ }^{*} p<0.05$,

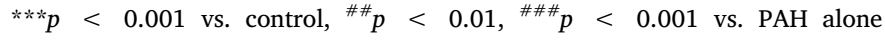
(Bonferroni's test).

induction of CYP1B1 and CYP1A1 mRNAs by VPA (Supplementary material 3).

Next, the effects of AEDs on CYP1 induction by PAHs were examined. Co-treatment with CBZ, LTG, LEV, and PHT for $24 \mathrm{~h}$ did not affect 3-MC-mediated induction of CYP1B1 and CYP1A1 mRNAs (Supplementary material 4). In contrast, VPA significantly enhanced the upregulation of CYP1B1 and CYP1A1 mRNAs by 3-MC (Fig. 5A). VPA also significantly increased the expression levels of CYP1B1 and CYP1A1 mRNAs induced by $\mathrm{B}[a] \mathrm{A}$ and $\mathrm{B}[a] \mathrm{P}$ (Fig. $5 \mathrm{~B}$ and $\mathrm{C}$ ). These effects were more remarkable in induction of CYP1A1 than CYP1B1.

\subsection{Effects of TSA on human CYP1 induction by 3-MC in MOG-G-CCM} cells

VPA is known to act as an inhibitor of histone deacetylases (HDACs) $[33,34]$. HDACs regulate the acetylation status of histones. HDAC inhibition promotes histone acetylation, resulting in the activation of gene expression [35]. A mechanism by which VPA augmented PAHmediated upregulation of CYP1 gene expression was considered to be due to inhibition of HDACs by VPA. To clarify whether CYP1 induction by 3-MC was potentiated by HDAC inhibition, the effects of an HDAC inhibitor on 3-MC-mediated induction were examined. TSA, a representative HDAC inhibitor [36], significantly enhanced 3-MC-mediated upregulation of CYP1A1 mRNA, whereas this inhibitor did not potentiate that of CYP1B1 mRNA (Fig. 6). 


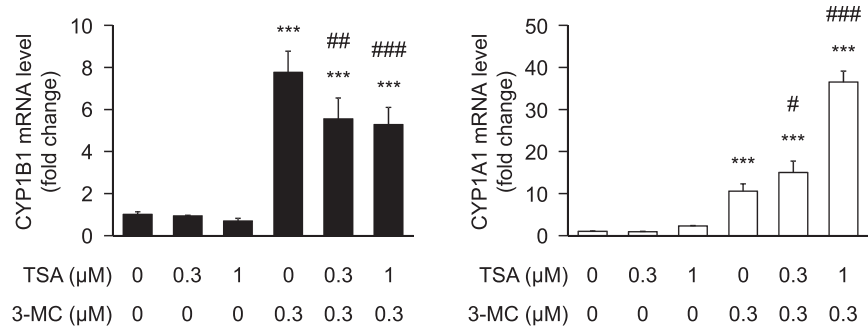

Fig. 6. Effects of TSA on CYP1 induction by 3-MC in MOG-G-CCM cells. MOGG-CCM cells were treated with TSA in the presence or absence of 3-MC for $24 \mathrm{~h}$. Expression levels of CYP1B1 and CYP1A1 mRNAs were determined by qPCR. Data are expressed as the mean \pm S.D. of triplicate determinations ( $n=4$ per an experiment). ${ }^{* * *} p<0.001$ vs. control, ${ }^{*} p<0.05,{ }^{*} p<0.01$, $\# \#$ \# $<0.001$ vs. 3-MC alone (Bonferroni's test).

\section{Discussion}

In the present study, we demonstrated that a variety of CYP isoforms, including CYP1B1 and CYP1A1, are expressed in human astrocytoma MOG-G-CCM cells. It has been reported that CYP1B1 and CYP1A1 are expressed in MOG-G-CCM cells [37-39]. To our knowledge, however, this is the first study to show the expression of many CYP isoforms other than CYP1B1 and CYP1A1 in this cell line. Furthermore, our results showed that CYP1B1 had the highest expression level among the CYP isoforms examined. To date, the expression of CYP1B1 has been found in astrocytes and neurons from various regions of the normal human brain (e.g., frontal cortex, hippocampus, cerebellum, etc.) [25]. Interestingly, the cellular distribution of CYP1B1 varies greatly among brain regions. The expression of CYP1B1 in glial cells, such as astrocytes and microglia, is detected in the frontal cortex, hippocampus, and cerebellum [25]. On the other hand, the neuronal expression of CYP1B1 is not found in the frontal cortex, although this expression is restricted to the granular layer of the hippocampus and glomeruli of the cerebellum [25]. These differences in cellular distribution are considered to be due to differences in cellular composition, cell density, and function of glial cells and neurons in individual brain regions. In addition to the normal brain, CYP1B1 is highly expressed in various brain tumors (glioblastoma, astrocytoma, neuroblastoma, etc.) [40-44]. In glial tumors, increased expression of CYP1B1 has been shown to be associated with decreased patient survival [42]. These findings suggest that CYP1B1 may play important roles not only in normal brain function but also in the pathogenesis and malignancy of brain tumors.

Although there have been several reports on the expression of CYP1B1 in MOG-G-CCM cells as described above, its subcellular localization was unclear. In this study, we demonstrated the possibility that CYP1B1 may be localized not only in the ER but also in the mitochondria of MOG-G-CCM cells. The mitochondrial localization of CYP1B1 has also been observed in some regions of the normal human brain [25] and the human neuroblastoma cell line SH-SY5Y [44]. Mitochondrial targeting of CYP1B1 has been reported to involve proteolytic processing of the $\mathrm{N}$-terminus of the nascent protein by a cytosolic endoprotease [45]. Further studies are needed to elucidate the role of CYP1B1 localized in the brain mitochondria.

There have been a few previous studies on the induction of CYP1B1 and/or CYP1A1 by PAHs, such as 7,12-dimethylbenz[ $a]$ anthracene and 3-MC, in MOG-G-CCM cells [38,39]. Our study confirmed that 3-MC and two tobacco smoke containing PAHs, $\mathrm{B}[a] \mathrm{A}$ and $\mathrm{B}[a] \mathrm{P}$, significantly induced the expression of CYP1B1 and CYP1A1 in MOG-GCCM cells. However, McFadyen et al. [39] reported that a 3-MCmediated increase in CYP1B1 mRNA level was not observed in this cell line. This discrepancy may be explained by the differences in concentrations of 3-MC tested; they used 3-MC at a very high concentration $(25 \mu \mathrm{M})$, whereas we applied this compound at a maximum of $1 \mu \mathrm{M}$. In this study, the induction of CYP1B1 by 3-MC reached a maximum level at $0.3 \mu \mathrm{M}$ and plateaued at $1 \mu \mathrm{M}$. These findings suggested that a high concentration of 3-MC (25 $\mu \mathrm{M})$ may lack the ability to induce the expression of CYP1B1 in MOG-G-CCM cells. Moreover, our study using AhR antagonist showed the involvement of AhR in the induction of CYP1B1 and CYP1A1 by 3-MC in MOG-G-CCM cells. B $[a] \mathrm{A}$ and $\mathrm{B}[a] \mathrm{P}$, like 3-MC, are also AhR ligands $[46,47]$. Tobacco smoke contains a variety of PAHs other than the compounds tested in this study [31]. Many PAHs including benzo[k]fluoranthene and chrysene, as well as B $[a] \mathrm{A}$ and $\mathrm{B}[a] \mathrm{P}$, have an ability to induce CYP1 expression via AhR signaling $[13,48]$. Our results indicated that MOG-G-CCM cells possess inducibilities of CYP1B1 and CYP1A1 by PAHs.

The results of expression analysis with AEDs revealed that only VPA induced the expression of CYP1B1 and CYP1A1 in MOG-G-CCM cells. In addition, the VPA-mediated induction of CYP1B1 and CYP1A1 was repressed by an AhR antagonist. These results suggest that VPA may induce the expression of CYP1B1 and CYP1A1 through the activation of AhR signaling. There are at least two mechanisms underlying the transcriptional activation of the CYP1 genes through the AhR; a liganddependent AhR activation by AhR agonists, such as 3-MC, and ligandindependent AhR activation by certain chemicals, such as omeprazole [29]. At present, however, it remains unclear whether VPA acts as an AhR ligand. The upregulation of CYP1A1 by VPA has been also observed in the human cerebral microvascular endothelial cell line hCMEC/D3 and human neuroblastoma cell lines UKF-NB-3 and UKFNB-4 $[49,50]$. Furthermore, several other HDAC inhibitors have been shown to possess an ability to induce the expression of CYP1B1 and/or CYP1A1 in some cell lines [49-52]. A recent study suggests that the induction of CYP1A1 by HDAC inhibitors is caused by increasing histone acetylation and the amount of AhR bound to the xenobiotic response element at the CYP1A1 gene promoter [49]. These findings suggest that the HDAC inhibition by VPA also may play an important role in the VPA-mediated upregulation of CYP1B1 and CYP1A1 in MOG-G-CCM cells. In contrast to VPA, CBZ, LTG, LEV, and PHT did not cause the induction of CYP1B1 and CYP1A1 in this cell line under the current conditions. Of these AEDs, CBZ and PHT are known to induce the expression of CYP2C and CYP3A [53]. Moreover, CBZ is also capable of inducing CYP1A2 in the liver [54,55]. However, there are no reports regarding the induction of CYP1B1 and CYP1A1 by CBZ, LTG, LEV, and PHT. At present, roles of these AEDs in the regulation of CYP1B1 and CYP1A1 gene expression remain to be elucidated.

The present study indicated that VPA alone among the AEDs tested enhanced the induction of CYP1B1 and CYP1A1 by PAHs in MOG-GCCM cells. This is the first report showing VPA-mediated potentiation of CYP1B1 induction by PAHs, although VPA has been reported to augment PAH-mediated CYP1A1 induction [56]. VPA has an ability to inhibit HDAC activity [33,34,49]. HDAC inhibition facilitates the acetylation of histone, resulting in the transcriptional activation of genes [35]. Thus, we considered a possibility that VPA-mediated enhancement of CYP1 induction by PAHs was caused by HDAC inhibition. To confirm this hypothesis, we examined the effects of TSA, a representative HDAC inhibitor, on 3-MC-mediated induction. The results showed that TSA augmented the induction of CYP1A1 by 3-MC. It has been shown that several HDAC inhibitors, including VPA and TSA, potentiated PAH-mediated CYP1A1 induction in other cell lines $[49,52,56,57]$. These results suggest that VPA may promote PAHmediated transcriptional activation of the CYP1A1 gene by increasing histone acetylation in MOG-G-CCM cells. On the other hand, TSA failed to potentiate 3-MC-mediated induction of CYP1B1 in this cell line. A similar result has been also observed in the human breast cancer cell line MCF-7 co-treated with $\mathrm{B}[\mathrm{a}] \mathrm{P}$ and TSA [51]. The reason why TSA was not responsive to $\mathrm{PAH}$-mediated CYP1B1 induction is unclear. In contrast to TSA, it has been reported that other HDAC inhibitors, butyric acid, panobinostat, and vorinostat, increased the expression of CYP1B1 induced by 2,3,7,8-tetrachlorodibenzo-p-dioxin, a potent AhR agonist, in the human colonic adenocarcinoma cell line Caco-2 [52]. 
These findings may partially explain the potential involvement of histone acetylation in VPA-mediated augmentation of CYP1B1 induction by PAHs in MOG-G-CCM cells.

In the present study, we identified part of the mechanism of high CYP1B1 and CYP1A1 expression in the brains of smokers reported previously by Toselli et al. [14]. Furthermore, among the AEDs tested, we demonstrated that only VPA augmented PAH-mediated CYP1 induction. CYP1B1 and CYP1A1 are known to be involved in the metabolism of estrogen, one of the neurosteroids $[15,58]$. It is suggested that neurosteroids play important roles in neural circuit building, brain repair, memory, learning, and cognitive functioning [59]. If excessive response of CYP1 genes to tobacco smoking is induced in the brains of smokers receiving VPA, this response may enhance estradiol metabolism in the brain and hence affect the maintenance of normal brain function. In addition, it has been reported that neurosteroids, especially allopregnanolone, have anticonvulsant effects [60]. These findings suggest that dysfunction of neurosteroid biosynthesis caused by smoking and VPA administration may lead to the onset of epileptic seizures. Further studies are needed to clarify the physiological functions of neurosteroids and the roles of cerebral CYP1 enzymes in epilepsy.

\section{Conclusion}

We demonstrated that human astrocytoma MOG-G-CCM cells expressed various CYP isoforms; CYP1B1 was most highly expressed, followed by CYP1A1. 3-MC, B $[a] \mathrm{A}, \mathrm{B}[a] \mathrm{P}$, and VPA effectively induced the expression of CYP1B1 and CYP1A1 in this cell line. In addition, VPA significantly potentiated the induction of CYP1B1 and CYP1A1 by these PAHs. Our results partially suggest that the VPA-mediated augmentation of CYP1 induction by PAHs is mediated by HDAC inhibition by VPA. Our study provided useful basic information regarding the effects of tobacco smoking and AEDs on brain function.

\section{Author contributions}

Participated in conception and design of the study: Shusuke Ozawa, Satoshi Yamaori, Shigeru Ohmori

Conducted experiments: Shusuke Ozawa, Satoshi Yamaori, Kaori Aikawa, Shinobu Kamijo

Performed data analysis: Shusuke Ozawa, Satoshi Yamaori, Kaori Aikawa, Shinobu Kamijo

Wrote or contributed to the writing of the manuscript: Shusuke Ozawa, Satoshi Yamaori, Shigeru Ohmori

\section{Acknowledgements}

None.

\section{Funding}

This work was supported in part by Grants-in-Aid for Encouragement of Scientists from the Ministry of Education, Culture, Sports, Science and Technology of Japan (Nos. 25926005, 26926003, 15H00481, 16H00486, and 17H00475).

\section{Declaration of competing interest}

The authors declare that there are no conflicts of interest.

\section{Appendix A. Supplementary data}

Supplementary data to this article can be found online at https:// doi.org/10.1016/j.lfs.2020.118140.

\section{References}

[1] A. Singh, S. Trevick, The epidemiology of global epilepsy, Neurol. Clin. 34 (2016) 837-847, https://doi.org/10.1016/j.ncl.2016.06.015.

[2] R. Kobau, C.A. Dilorio, P.H. Price, D.J. Thurman, L.M. Martin, D.L. Ridings, T.R. Henry, Prevalence of epilepsy and health status of adults with epilepsy in Georgia and Tennessee: Behavioral Risk Factor Surveillance System, 2002, Epilepsy Behav. 5 (2004) 358-366, https://doi.org/10.1016/j.yebeh.2004.02.007.

[3] P.L. Ferguson, J. Chiprich, G. Smith, B. Dong, B.B. Wannamaker, R. Kobau, D.J. Thurman, A.W. Selassie, Prevalence of self-reported epilepsy, health care access, and health behaviors among adults in South Carolina, Epilepsy Behav. 13 (2008) 529-534, https://doi.org/10.1016/j.yebeh.2008.05.005.

[4] O. Torriani, F. Vuilleumier, T. Perneger, P.-A. Despland, M. Maeder, A.-C. HéritierBarras, S. Vulliemoz, M. Seeck, A.O. Rossetti, F. Picard, Epilepsy and tobacco smoking: a cross-sectional study, J. Neurol. 263 (2016) 2057-2064, https://doi. org/10.1007/s00415-016-8228-7.

[5] U.S. Department of Health and Human Services, The Health Consequences of Smoking - 50 Years of Progress: A Report of the Surgeon General, US Department of Health and Human Services, Centers for Disease Control and Prevention, National Center for Chronic Disease Prevention and Health Promotion, Office on Smoking and Health, (2014) (doi:NBK179276).

[6] B.A. Dworetzky, E.B. Bromfield, M.K. Townsend, J.H. Kang, A prospective study of smoking, caffeine, and alcohol as risk factors for seizures or epilepsy in young adult women: data from the Nurses' Health Study II, Epilepsia 51 (2010) 198-205, https://doi.org/10.1111/j.1528-1167.2009.02268.x.

[7] L. Rong, A.T. Frontera Jr., S.R. Benbadis, Tobacco smoking, epilepsy, and seizures, Epilepsy Behav. 31 (2014) 210-218, https://doi.org/10.1016/j.yebeh.2013.11. 022 .

[8] C. Minardi, R. Minacapelli, P. Valastro, F. Vasile, S. Pitino, P. Pavone, M. Astuto, P. Murabito, Epilepsy in children: from diagnosis to treatment with focus on emergency, J. Clin. Med. 8 (2019) 39, https://doi.org/10.3390/jcm8010039.

[9] D.R. Nelson, L. Koymans, T. Kamataki, J.J. Stegeman, R. Feyereisen, D.J. Waxman, M.R. Waterman, O. Gotoh, M.J. Coon, R.W. Estabrook, I.C. Gunsalus, D.W. Nebert, P450 superfamily: update on new sequences, gene mapping, accession numbers and nomenclature, Pharmacogenetics 6 (1996) 1-42, https://doi.org/10.1097/ 00008571-199602000-00002.

[10] F. Dutheil, P. Beaune, M.A. Loriot, Xenobiotic metabolizing enzymes in the central nervous system: contribution of cytochrome P450 enzymes in normal and pathological human brain, Biochimie 90 (2008) 426-436, https://doi.org/10.1016/j. biochi.2007.10.007.

[11] J.C. Willey, E.L. Coy, M.W. Frampton, A. Torres, M.J. Apostolakos, G. Hoehn, W.H. Schuermann, W.G. Thilly, D.E. Olson, J.R. Hammersley, C.L. Crespi, M.J. Utell, Quantitative RT-PCR measurement of cytochromes p450 1A1, 1B1, and 2B7, microsomal epoxide hydrolase, and NADPH oxidoreductase expression in lung cells of smokers and nonsmokers, Am. J. Respir. Cell Mol. Biol. 17 (1997) 114-124, https://doi.org/10.1165/ajrcmb.17.1.2783.

[12] J.H. Kim, M.E. Sherman, F.C. Curriero, F.P. Guengerich, P.T. Strickland, T.R. Sutter, Expression of cytochromes P450 1A1 and 1B1 in human lung from smokers, nonsmokers, and ex-smokers, Toxicol. Appl. Pharmacol. 199 (2004) 210-219, https:// doi.org/10.1016/j.taap.2003.11.015.

[13] A. Lampen, B. Ebert, L. Stumkat, J. Jacob, A. Seidel, Induction of gene expression of xenobiotic metabolism enzymes and ABC-transport proteins by $\mathrm{PAH}$ and a reconstituted PAH mixture in human Caco-2 cells, Biochim. Biophys. Acta Gene Struct. Expr. 1681 (2004) 38-46, https://doi.org/10.1016/j.bbaexp.2004.09.010.

[14] F. Toselli, I. de Waziers, M. Dutheil, M. Vincent, P.A. Wilce, P.R. Dodd, P. Beaune, M.-A. Loriot, E.M.J. Gillam, Gene expression profiling of cytochromes P450, ABC transporters and their principal transcription factors in the amygdala and prefrontal cortex of alcoholics, smokers and drug-free controls by qRT-PCR, Xenobiotica 45 (2015) 1129-1137, https://doi.org/10.3109/00498254.2015.1040102.

[15] A.J. Lee, M.X. Cai, P.E. Thomas, A.H. Conney, B.T. Zhu, Characterization of the oxidative metabolites of $17 \beta$-estradiol and estrone formed by 15 selectively expressed human cytochrome P450 isoforms, Endocrinology 144 (2003) 3382-3398, https://doi.org/10.1210/en.2003-0192.

[16] Y. Tsuchiya, M. Nakajima, T. Yokoi, Cytochrome P450-mediated metabolism of estrogens and its regulation in human, Cancer Lett. 227 (2005) 115-124, https:// doi.org/10.1016/j.canlet.2004.10.007.

[17] T. Takezawa, T. Matsunaga, K. Aikawa, K. Nakamura, S. Ohmori, Lower expression of HNF4 $\alpha$ and PGC1 $\alpha$ might impair rifampicin-mediated CYP3A4 induction under conditions where PXR is overexpressed in human fetal liver cells, Drug Metab. Pharmacokinet. 27 (2012) 430-438, https://doi.org/10.2133/dmpk.DMPK-11-RG126.

[18] M. Nishimura, H. Yoshitsugu, S. Naito, I. Hiraoka, Evaluation of gene induction of drug-metabolizing enzymes and transporters in primary culture of human hepatocytes using high-sensitivity real-time reverse transcription PCR, Yakugaku Zasshi 122 (2002) 339-361, https://doi.org/10.1248/yakushi.122.339.

[19] L.G. Yengi, Q. Xiang, J. Pan, J.A. Scatina, J. Kao, S.E. Ball, R. Fruncillo, G. Ferron, C.R. Wolf, Quantitation of cytochrome P450 mRNA levels in human skin, Anal. Biochem. 316 (2003) 103-110, https://doi.org/10.1016/S0003-2697(03)00042-3.

[20] W. Cui, D.D. Taub, K. Gardner, qPrimerDepot: a primer database for quantitative real time PCR, Nucleic Acids Res. 35 (2007) D805-D809, https://doi.org/10.1093/ nar/gkl767.

[21] S. Yamaori, H. Yamazaki, S. Iwano, K. Kiyotani, K. Matsumura, T. Saito, A. Parkinson, K. Nakagawa, T. Kamataki, Ethnic differences between Japanese and Caucasians in the expression levels of mRNAs for CYP3A4, CYP3A5 and CYP3A7: lack of co-regulation of the expression of CYP3A in Japanese livers, Xenobiotica 35 
(2005) 69-83, https://doi.org/10.1080/00498250400021796.

[22] U.K. Laemmli, Cleavage of structural proteins during the assembly of the head of bacteriophage T4, Nature 227 (1970) 680-685, https://doi.org/10.1038/ $227680 \mathrm{a} 0$.

[23] E.P.A. Neve, M. Ingelman-Sundberg, Intracellular transport and localization of microsomal cytochrome P450, Anal. Bioanal. Chem. 392 (2008) 1075-1084, https://doi.org/10.1007/s00216-008-2200-z.

[24] B. Walther, J.F. Ghersi-Egea, A. Minn, G. Siest, Subcellular distribution of cytochrome P-450 in the brain, Brain Res. 375 (1986) 338-344, https://doi.org/10. 1016/0006-8993(86)90754-7.

[25] F. Dutheil, S. Dauchy, M. Diry, V. Sazdovitch, O. Cloarec, L. Mellottée, I. Bièche, M. Ingelman-Sundberg, J.-P. Flinois, I. de Waziers, P. Beaune, X. Declèves, C. Duyckaerts, M.-A. Loriot, Xenobiotic-metabolizing enzymes and transporters in the normal human brain: regional and cellular mapping as a basis for putative roles in cerebral function, Drug Metab. Dispos. 37 (2009) 1528-1538, https://doi.org/ 10.1124/dmd.109.027011.

[26] I. Wada, D. Rindress, P.H. Cameron, W.J. Ou, J.J. Doherty 2nd, D. Louvard, A.W. Bell, D. Dignard, D.Y. Thomas, J.J. Bergeron, SSR $\alpha$ and associated calnexin are major calcium binding proteins of the endoplasmic reticulum membrane, $\mathrm{J}$. Biol. Chem. 266 (1991) 19599-19610 https://www.ncbi.nlm.nih.gov/pubmed/ 1918067.

[27] M. Zeviani, M. Nakagawa, J. Herbert, M.I. Lomax, L.I. Grossman, A.A. Sherbany, A.F. Miranda, S. DiMauro, E.A. Schon, Isolation of a cDNA clone encoding subunit IV of human cytochrome c oxidase, Gene 55 (1987) 205-217 http://www.ncbi.nlm. nih.gov/pubmed/2444497.

[28] M.S. Denison, J.P. Whitlock Jr., Xenobiotic-inducible transcription of cytochrome P450 genes, J. Biol. Chem. 270 (1995) 18175-18178, https://doi.org/10.1074/jbc. 270.31.18175.

[29] Y. Fujii-Kuriyama, J. Mimura, Molecular mechanisms of AhR functions in the regulation of cytochrome P450 genes, Biochem. Biophys. Res. Commun. 338 (2005) 311-317, https://doi.org/10.1016/j.bbrc.2005.08.162.

[30] K.J. Smith, I.A. Murray, R. Tanos, J. Tellew, A.E. Boitano, W.H. Bisson, S.K. Kolluri, M.P. Cooke, G.H. Perdew, Identification of a high-affinity ligand that exhibits complete aryl hydrocarbon receptor antagonism, J. Pharmacol. Exp. Ther. 338 (2011) 318-327, https://doi.org/10.1124/jpet.110.178392.

[31] D. Moir, W.S. Rickert, G. Levasseur, Y. Larose, R. Maertens, P. White, S. Desjardins, A comparison of mainstream and sidestream marijuana and tobacco cigarette smoke produced under two machine smoking conditions, Chem. Res. Toxicol. 21 (2008) 494-502, https://doi.org/10.1021/tx700275p.

[32] P.N. Patsalos, E.P. Spencer, D.J. Berry, Therapeutic drug monitoring of antiepileptic drugs in epilepsy: a 2018 update, Ther. Drug Monit. 40 (2018) 526-548, https:// doi.org/10.1097/FTD.0000000000000546.

[33] C.J. Phiel, F. Zhang, E.Y. Huang, M.G. Guenther, M.A. Lazar, P.S. Klein, Histone deacetylase is a direct target of valproic acid, a potent anticonvulsant, mood stabilizer, and teratogen, J. Biol. Chem. 276 (2001) 36734-36741, https://doi.org/10. 1074/jbc.M101287200.

[34] M. Göttlicher, S. Minucci, P. Zhu, O.H. Krämer, A. Schimpf, S. Giavara, J.P. Sleeman, F. Lo Coco, C. Nervi, P.G. Pelicci, T. Heinzel, Valproic acid defines a novel class of HDAC inhibitors inducing differentiation of transformed cells, EMBO J. 20 (2001) 6969-6978, https://doi.org/10.1093/emboj/20.24.6969.

[35] M. Ziemka-Nalecz, J. Jaworska, J. Sypecka, T. Zalewska, Histone deacetylase inhibitors: a therapeutic key in neurological disorders? J. Neuropathol. Exp. Neurol. 77 (2018) 855-870, https://doi.org/10.1093/jnen/nly073.

[36] M. Yoshida, M. Kijima, M. Akita, T. Beppu, Potent and specific inhibition of mammalian histone deacetylase both in vivo and in vitro by trichostatin A, J. Biol. Chem. 265 (1990) 17174-17179 https://www.ncbi.nlm.nih.gov/pubmed/ 2211619.

[37] C.R.M. Rieder, D.B. Ramsden, A.C. Williams, Cytochrome P450 1 B1 mRNA in the human central nervous system, J. Clin. Pathol. 51 (1998) 138-142, https://doi.org/ 10.1136/mp.51.3.138.

[38] C.R.M. Rieder, R.B. Parsons, N.J.S. Fitch, A.C. Williams, D.B. Ramsden, Human brain cytochrome P450 1B1: immunohistochemical localization in human temporal lobe and induction by dimethylbenz(a)anthracene in astrocytoma cell line (MOG-GCCM), Neurosci. Lett. 278 (2000) 177-180, https://doi.org/10.1016/s03043940(99)00932-5.

[39] M.C.E. McFadyen, P.H. Rooney, W.T. Melvin, G.I. Murray, Quantitative analysis of the Ah receptor/cytochrome P450 CYP1B1/CYP1A1 signalling pathway, Biochem. Pharmacol. 65 (2003) 1663-1674, https://doi.org/10.1016/s0006-2952(03) $00111-4$

[40] G.I. Murray, M.C. Taylor, M.C.E. McFadyen, J.A. McKay, W.F. Greenlee, M.D. Burke, W.T. Melvin, Tumor-specific expression of cytochrome P450 CYP1B1, Cancer Res. 57 (1997) 3026-3031 https://www.ncbi.nlm.nih.gov/pubmed/ 9230218.

[41] J. Liu, Q. Wang, D.-C. Wu, X.-W. Wang, Y. Sun, X.-Y. Chen, K.-L. Zhang, H. Li, Differential regulation of CYP1A1 and CYP1B1 expression in resveratrol-treated human medulloblastoma cells, Neurosci. Lett. 363 (2004) 257-261, https://doi. org/10.1016/j.neulet.2004.03.075.
[42] J.A. Barnett, D.L. Urbauer, G.I. Murray, G.N. Fuller, A.B. Heimberger, Cytochrome P450 1B1 expression in glial cell tumors: an immunotherapeutic target, Clin. Cancer Res. 13 (2007) 3559-3567, https://doi.org/10.1158/1078-0432.CCR-06-2430.

[43] P. Stavrinou, M.-C. Mavrogiorgou, K. Polyzoidis, V. Kreft-Kerekes, M. Timmer, M. Marselos, P. Pappas, Expression profile of genes related to drug metabolism in human brain tumors, PLoS One 10 (2015) e0143285, , https://doi.org/10.1371 journal.pone.0143285.

[44] Z. Yu, X. Tian, Y. Peng, Z. Sun, C. Wang, N. Tang, B. Li, Y. Jian, W. Wang, X. Huo, $\mathrm{X}$. Ma, Mitochondrial cytochrome P450 (CYP) 1B1 is responsible for melatonininduced apoptosis in neural cancer cells, J. Pineal Res. 65 (2018) e12478, , https:// doi.org/10.1111/jpi.12478.

[45] S. Bansal, A.N. Leu, F.J. Gonzalez, F.P. Guengerich, A.R. Chowdhury, H.K. Anandatheerthavarada, N.G. Avadhani, Mitochondrial targeting of cytochrome P450 (CYP) 1B1 and its role in polycyclic aromatic hydrocarbon-induced mitochondrial dysfunction, J. Biol. Chem. 289 (2014) 9936-9951, https://doi.org/10 1074/jbc.M113.525659.

[46] P.A. Harper, C.L. Golas, A.B. Okey, Characterization of the Ah receptor and aryl hydrocarbon hydroxylase induction by 2,3,7,8-tetrachlorodibenzo-p-dioxin and benz(a)anthracene in the human A431 squamous cell carcinoma line, Cancer Res. 48 (1988) 2388-2395 https://pubmed.ncbi.nlm.nih.gov/2833345/.

[47] P.A. Harper, R.D. Prokipcak, L.E. Bush, C.L. Golas, A.B. Okey, Detection and characterization of the Ah receptor for 2,3,7,8-tetrachlorodibenzo-p-dioxin in the human colon adenocarcinoma cell line LS180, Arch. Biochem. Biophys. 290 (1991) 27-36, https://doi.org/10.1016/0003-9861(91)90587-9.

[48] J. Vondráček, K. Pěnčíková, J. Neča, M. Ciganek, A. Grycová, Z. Dvořák, M. Machala, Assessment of the aryl hydrocarbon receptor-mediated activities of polycyclic aromatic hydrocarbons in a human cell-based reporter gene assay, Environ. Pollut. 220 ( (2017) 307-316, https://doi.org/10.1016/j.envpol.2016.09. 064.

[49] D. You, X. Wen, L. Gorczyca, A. Morris, J.R. Richardson, L.M. Aleksunes, Increased MDR1 transporter expression in human brain endothelial cells through enhanced histone acetylation and activation of aryl hydrocarbon receptor signaling, Mol. Neurobiol. 56 (2019) 6986-7002, https://doi.org/10.1007/s12035-019-1565-7.

[50] J. Hřebačková, J. Poljaková, T. Eckschlager, J. Hraběta, P. Procházka, S. Smutný, M. Stiborová, Histone deacetylase inhibitors valproate and trichostatin A are toxic to neuroblastoma cells and modulate cytochrome P450 1A1, 1B1 and 3A4 expression in these cells, Interdiscip. Toxicol. 2 (2009) 205-210, https://doi.org/10. 2478/v10102-009-0019-x.

[51] L.A. Hooven, B. Mahadevan, C. Keshava, C. Johns, C. Pereira, D. Desai, S. Amin, A. Weston, W.M. Baird, Effects of suberoylanilide hydroxamic acid and trichostatin A on induction of cytochrome P450 enzymes and benzo[a]pyrene DNA adduct formation in human cells, Bioorg. Med. Chem. Lett. 15 (2005) 1283-1287, https:// doi.org/10.1016/j.bmcl.2005.01.032.

[52] U.-H. Jin, Y. Cheng, H. Park, L.A. Davidson, E.S. Callaway, R.S. Chapkin, A. Jayaraman, A. Asante, C. Allred, E.A. Weaver, S. Safe, Short chain fatty acids enhance aryl hydrocarbon (Ah) responsiveness in mouse colonocytes and Caco-2 human colon cancer cells, Sci. Rep. 7 (2017) 10163, , https://doi.org/10.1038/ S41598-017-10824-x.

[53] G.D. Anderson, Pharmacogenetics and enzyme induction/inhibition properties of antiepileptic drugs, Neurology 63 (2004) S3-S8, https://doi.org/10.1212/wnl.63. 10_suppl_4.s3.

[54] A.C. Parker, P. Pritchard, T. Preston, I. Choonara, Induction of CYP1A2 activity by carbamazepine in children using the caffeine breath test, Br. J. Clin. Pharmacol. 45 (1998) 176-178, https://doi.org/10.1046/j.1365-2125.1998.00684.x.

[55] I. Sugiyama, N. Murayama, A. Kuroki, J. Kota, S. Iwano, H. Yamazaki, T. Hirota, Evaluation of cytochrome P450 inductions by anti-epileptic drug oxcarbazepine, 10-hydroxyoxcarbazepine, and carbamazepine using human hepatocytes and HepaRG cells, Xenobiotica 46 (2016) 765-774, https://doi.org/10.3109/ 00498254.2015 .1118774

[56] R. Vrzal, A. Doricakova, A. Novotna, P. Bachleda, M. Bitman, P. Pavek, Z. Dvorak, Valproic acid augments vitamin D receptor-mediated induction of CYP24 by vitamin D3: a possible cause of valproic acid-induced osteomalacia? Toxicol. Lett. 200 (2011) 146-153, https://doi.org/10.1016/j.toxlet.2010.11.008.

[57] O. Zapletal, Z. Tylichová, J. Neča, J. Kohoutek, M. Machala, A. Milcová, M. Pokorná, J. Topinka, M.P. Moyer, J. Hofmanová, A. Kozubík, J. Vondráček, Butyrate alters expression of cytochrome P450 1A1 and metabolism of benzo[a] pyrene via its histone deacetylase activity in colon epithelial cell models, Arch. Toxicol. 91 (2017) 2135-2150, https://doi.org/10.1007/s00204-016-1887-4.

[58] C.L. Hayes, D.C. Spink, B.C. Spink, J.Q. Cao, N.J. Walker, T.R. Sutter, 17 $\beta$-Estradio hydroxylation catalyzed by human cytochrome P450 1B1, Proc. Natl. Acad. Sci. U. S. A. 93 (1996) 9776-9781, https://doi.org/10.1073/pnas.93.18.9776.

[59] M.F. Rossetti, M.J. Cambiasso, M.A. Holschbach, R. Cabrera, Oestrogens and progestagens: synthesis and action in the brain, J. Neuroendocrinol. 28 (2016) 1-11, https://doi.org/10.1111/jne.12402.

[60] D.S. Reddy, Role of hormones and neurosteroids in epileptogenesis, Front. Cell. Neurosci. 7 (2013) 115, https://doi.org/10.3389/fncel.2013.00115. 